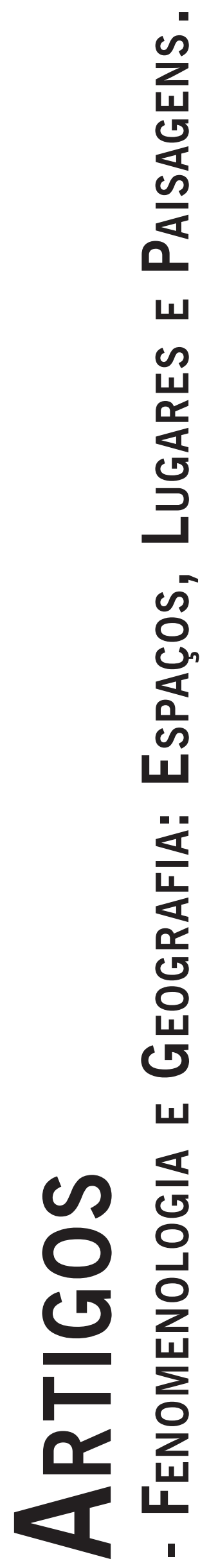




\title{
HUSSERL, MUNDO-DA-VIDA E GEOGRAFIA
}

\author{
Husserl, Life-world and Geography \\ Husserl, Mundo de la Vida y Geografía
}

RAFAEL BASTOS FERREIRA

\begin{abstract}
Resumo: O trabalho tem como proposta fazer um aprofundamento fenomenológico sobre o conceito husserliano do "mundo-davida” (Lebenswelt) na ciência geográfica. Deseja-se, com isso, apresentar considerações pertinentes que nos forneça elementos positivos para produzir um debate em torno desse tema ainda pouco discutido nos seus pressupostos teóricos nesta disciplina na atualidade. Com efeito, o texto irá expor três movimentos de reflexão: a) apresentar em linhas gerais o tratamento husserliano do conceito de mundo-da-vida e o debate que lhe circunda; b) compreender na tradição da geografia humanista e fenomenológica, a partir de alguns autores, o modo como foi interpretado e requerido. Por último, c) visamos ampliar e (re) afirmar o mundo-da-vida como um horizonte e solo fundamental no estudo da ciência geográfica.
\end{abstract}

Palavras-chave: Fenomenologia; Conhecimento; Geografia fenomenológica.

\begin{abstract}
The paper aims to make a phenomenological deepening of the Husserl's concept of the "life-world" (Lebenswelt) in geographical science. To want it, make relevant considerations to provide us with positive elements to produce a debate on this subject still little discussed in the assumptions in this discipline today. Indeed, the text will present three reflection of movements: a) to outline the Husserl's treatment of the concept of life-world and the debate that surrounds him; b) understand the tradition of humanistic and phenomenological geography, from some authors, the way it was interpreted and applied. Finally, we aim to expand and (re) affirm the life-world as a fundamental horizon and soil in the geographical science study nowadays.
\end{abstract}

Keywords: Phenomenology; knowledge; Phenomenological geography.

Resumen: El documento tiene como objetivo hacer una profundización del concepto fenomenológico de Husserl del "mundo de la vida" (Lebenswelt) en la ciencia geográfica. Que desearlo, hacer las consideraciones pertinentes para proporcionarnos elementos positivos para producir un debate sobre este tema aún poco discutidos en los supuestos en esta disciplina en la actualidad. De hecho, el texto presentará tres reflejos de movimientos: a) para delinear el tratamiento del concepto de mundo de la vida y la cola debate le rodea de la Husserl; b) comprender la tradición de la geografía humanista y fenomenológica, de algunos autores, la forma en que se interpreta y se aplica. Por último, nuestro objetivo es ampliar y (re) afirmar el mundo de la vida como horizonte fundamental y el suelo en el estudio de la ciencia geográfica en la actualidad.

Palabras-clave: Fenomenología; Conocimiento; Geografía fenomenológica.

\section{Introdução}

Por algum tempo a filosofia foi decisiva para se pensar as bases teórico-conceituais da ciência geográfica (Casey, 2001). Conforme Estébanez (1982), já nos anos de 1950 pouco se buscou nesta disciplina uma fundamentação, assim como, em relação às ciências sociais. A partir da década de 1970 este quadro se reverteu: as aproximações visavam, quase exclusivamente, uma renovação da disciplina contra a corrente quantitativa e do positivismo lógico. Procuravam estes geógrafos - marxistas, fenomenólogos, entre outras alternativas teóricas - por em pauta questões que envolviam o debate sobre o conhecimento na disciplina. As preocupações giravam em torno dos procedimentos científicos, objetos de investigação e métodos com o objetivo de compreender os novos problemas contemporâneos humanos (sociais, políticos, econômicos, urbanos, ambientais, etc.). Categorias como território, paisagem e região passaram a ser rediscutidos, porém, conforme Moreira (2000), a renovação da geografia percorreu pela questão do espaço.

Nos dias atuais e de modo geral, a ciência geográfica pouco tem buscado na filosofia fundamentos para uma crítica do conhecimento. Contrariamente a este último caso, nossa exposição busca uma fundamentação na filosofia fenomenológica de Edmund Husserl (1859-1938) no que tange o conceito do mundo-da-vida (Lebenswelt) a fim de uma incursão teórica à ciência geográfica. De acordo com Marandola Jr. (2005) trazer a fenomenologia para geografia é tratar, justamente, dos problemas do conhecimento e, portanto, continuamos a entender do papel da filosofia como um caminho possível de rediscutir alguns temas e ampliar outros no campo da ciência. É nesse sentido, que objetivamos ampliar o conceito do mundo-da-vida já em curso desde o final do século XX, no entanto, perde interesse neste século pelos geógrafos.

O pensamento fenomenológico na ciência geográfica se efetuou, especialmente, na tradição da geografia hu- 
manista (entre os anos de 1960 e 1980), no entanto, cabe ressaltar, “[...] que nem toda geografia humanista é fenomenológica” (Marandola Jr., 2013, p. 50). De antemão, ponderamos que este texto não visa relembrar esta tradição, mas sim, alguns autores que contribuíram para o tema que aqui pretendemos desenvolver: a importância do conceito mundo-da-vida (Lebenswelt) para o pensamento geográfico. Tratamos, portanto, de esboçar uma geografia fenomenológica do mundo-da-vida, entendendo este pressuposto como um campo de investigação voltada para os problemas e dificuldades do conhecimento; logo, ressaltamos que este conceito não ganhará aqui qualquer conotação de uma outra categoria de análise geográfica, tal como, espaço, território, paisagem ou região. Feitas estas ressalvas, vejamos na próxima seção os principais elementos da crítica fenomenológica levantada pelos geógrafos humanistas, ou melhor, no seu fundamento, em que sentido a fenomenologia aparece para um pensamento de renovação e alternativo.

\section{A fenomenologia como um horizonte crítico e alternativo no pensamento geográfico humanista}

Com argumentos e temas filosóficos que cunhavam os grandes fenomenólogos do século XX como Husserl (mundo-da-vida), Heidegger (ser-no-mundo e habitar), Merleau-Ponty (corpo-sujeito) e Sartre (liberdade humana e existencialismo), geógrafos humanistas buscaram formas alternativas e de renovação em meados dos anos 1970. Para Sanguin (1981) trata-se de uma reação contra a ciência neo-positivista e em grande parte, às bases da tradição da fenomenologia, estabelecendo na experiência o horizonte do conhecimento (Entrikin, 1976). Desse modo, o homem passou a ser considerado nos seus diversos atributos mundanos: suas emoções, percepções, valores, etc. Assim, foram levados em conta não somente as qualidades materiais da vida cotidiana, mas sobretudo, a própria subjetividade humana como uma constituição fundamental. Entendemos desse modo, então que "[...] qualquer pessoa que inspecione o mundo à sua volta é, em alguma medida, um geógrafo" (Lowenthal, 1961, p. 242, tradução nossa). ${ }^{1}$ Desse modo, compreender a geografia significou, necessariamente, compreender o próprio homem enquanto ser geográfico e sujeito do conhecimento.

Categorias como "Lugar", "Paisagem" e "Espaço" passaram a ser reinterpretados e ressignificados a partir do horizonte de uma geografia sob as bases da fenomenologia. Sem desconsiderar o conceito de espaço geográfico (normalmente pautado sob o arcabouço do materialismo histórico), geógrafos humanistas se dedicaram ao que se chamou de espaço vivido enquanto um conceito que priorizasse o estudo da experiência geográfica do ser-e-

"[...] anyone who inspects the world around him is in some measure a geographer". -estar-no-mundo. Sanguin (1981) lembra que o espaço vivido se tornou o mundo da experiência imediata anterior às ideias científicas. Decerto, este entendimento ganhou compreensões semelhantes ao conceito do mundo-da-vida (pré-teórico), no entanto, pensamos: se o espaço vivido for compreendido como uma dimensão da vida cotidiana este debate merece maiores explicações, uma vez, entendermos que mundo-da-vida e cotidiano expressam entendimentos particulares (Ferreira, 2015).

Portanto, geógrafos de base fenomenológica ergueram um regresso à experiência em busca de um retorno ao conhecimento originário, da qual, emanaria a própria essência da geografia, isto é, o reencontro de uma geografia que precede a sua própria cientificidade: uma geografia existencial que põe o homem lançado no mundo e, por outro lado, onde o mundo se expõe como horizonte de ação, destino e finalidade.

No entanto, o que significaria este retorno em seu sentido geral? Husserl (1900-1901/2001) em Investigações Lógicas (Logische Untersuchungen) no conjunto de sua crítica ao psicologismo experimental (naturalismo) e à teoria do conhecimento (no plano da lógica) ergueu o seguinte princípio como necessidade fundamental para uma nova tarefa da filosofia e do conhecimento: "devemos voltar às coisas mesmas" (Wir wollen auf die "Sachen selbst” Zurückgehen). Iniciou-se então uma radicalização que buscava inquirir o sentido primeiro da fundação do conhecimento: foi na obra "Ideen I" de 1913 que se apresentou a redução fenomenológica como método de investigação do eidos. Em geral, Husserl pretendia a superação da metafísica tradicional e do racionalismo científico (positivista), desse modo, partiu da tese, "voltar às coisas mesmas”, em busca de uma intuição originária (intuição das essências) do conhecimento e a chamou como o princípio dos princípios (Dartigues, 1972/1992).

Retornar às coisas mesmas é retornar a este mundo anterior ao conhecimento do qual o conhecimento sempre fala, e em relação ao qual toda determinação científica é abstrata, significativa e dependente, como a geografia em relação à paisagem - primeiramente nós aprendemos o que é uma floresta, um prado ou um riacho. (Merleau-Ponty, 1945/1999, p. 4)

Em seu rigor, da qual a ciência conduziu timidamente, Husserl buscou neste princípio alcançar a intuição pura (Moran, 2002). O que se pretendia era refundar as bases do conhecimento (evidente e apodítico - indubitável) fazendo da epoché seu método exigente. Portanto, "voltar" representa a tarefa radical da fenomenologia de renovação sobre os imperativos exacerbados da racionalidade científica que se constituíram no final do século XIX. Retornar ao mundo que precede o conhecimento, conforme apontou Merleau-Ponty, não trata tão-somente de uma crítica epistemológica e do conhecimento, mais do que isso, é um descortinar da vida humana realmente significativa, 
de um sujeito situado e relacionado com as coisas que os cercam e que lhes atribui sentido de mundo: em última análise, é um retorno ao mundo-da-vida esquecido e negligenciado pelo objetivismo científico.

Husserl (1936/2012) em "Crise" (Die Krisis der Europäischen Wissenschaften und die transzendentale Phänomenologia, 1936) tratou desse tema com atenção. Nesta obra o autor acentua uma crítica radical à filosofia e, sobretudo, à ciência, erguendo a necessidade de um retorno ao mundo-da-vida em detrimento de uma decadência ética e moral do seu tempo - a perda de sentido da ciência para a existência humana e, portanto, revelando a crise do próprio homem. Esta necessidade de renovação repercutiu de forma positiva; algumas ciências de abordagens fenomenológicas tomaram como base o estudo do mundo-da-vida vislumbrando novas reorientações. Do mesmo modo, se conduziu no pensamento de alguns geógrafos humanistas (Buttimer, 1976, Relph, 1976/1979) e, portanto, tornando-o como base fundamental para o estudo da experiência (geográfica). Não obstante ao que apontou Merleau-Ponty, se buscou, metodologicamente, abster provisoriamente do conhecimento já tematizado pela ciência e caminhar para o reencontro de uma geografia pré-científica, não sistemática. Em resumo, de acordo com Entrikin (1976) e Pickles (1985), o conceito fenomenológico mais utilizado na relação entre as ciências sociais e a fenomenologia foi o de mundo-da-vida.

Algumas críticas conduziam os textos de fenomenólogos ao trazerem esta concepção como necessidade de um retorno do qual a ciência moderna negligenciou: as ciências modernas passaram a trabalhar sobre seus próprios pressupostos lógicos. Com pouca questionalibilidade sobre suas práticas e à realidade, se constituíram como "ciências de fatos", pautados na primazia de uma racionalidade exacerbada e, portanto, residindo num realismo ingênuo. Portanto, o mundo-da-vida significaria, nesse sentido, retornar a uma evidencia originária da experiência humana (Husserl, 1936/2012) que colocasse fora de vigência todos os conteúdos do mundo objetivo (existentes). Foi nesta relação entre mundo-da-vida (lugar ou espaço vivido) e experiência (geográfica) que os geógrafos humanistas conduziram suas investigações.

Para Entrikin (1976) a tradição fenomenológica se apresentou mais no seu horizonte crítico do que uma alternativa aos problemas da ciência geográfica. Não obstante, acreditamos que o tema mundo-da-vida na geografia traz a possibilidade do conjunto de três críticas: da razão, epistemológica e do conhecimento. Cabe ressaltar, que a ordem abaixo não visa demostrar qualquer grau de importância neste momento. Vejamos de forma breve.

1) A primeira se apresenta em sentido lato, isto é, o distanciamento da ciência com a vida humana ordinária. Apesar de todo êxito da ciência positivista como aponta em seu § 1 em "Crise", a vivência de um tempo conturbado e de profunda crise na Europa, fez com que Husserl aumentasse as dúvidas sobre a razão científica e sua tarefa.
Sem promover possibilidades melhores para a humanidade e sua condução, diz: "Na urgência de nossa vida ouvimos - esta ciência nada tem a nos dizer. [...] Meras ciências de fatos fazem meros homens de fatos" (Husserl, 1936/2012, p. 3). Confiantes com seus pressupostos metafísicos, a ciência moderna enquanto sentido de prosperity, o ser humano passou, por um lado, “[...] senão um mero espectador da ordem mecânica de um mundo indiferente, e, por outro, reprodutor eficaz de resultados fenomênicos" (Ferraz, 2004, p. 355). Ainda hoje temos fortes evidências desse desarraigamento da ciência e, sobretudo, das instituições sobre o mundo-da-vida.

2) A crítica epistemológica reside no próprio advento das ciências modernas no final do século XIX na sua conduta metódica, isto é, às bases de um pensamento natural e da matemática. Em "A filosofia como ciência de rigor”, Husserl (1911/1965) argumenta o naturalismo como consequência do descobrimento da natureza considerada como unidade do ser espaço-temporal conforme as leis naturais exatas. Para Dilthey (1910/2010, p. 33) "A construção das ciências naturais é determinada pelo modo como seu objeto, a natureza, é dado”. Husserl (1936/2012) considera a fonte originária desses princípios na matemática de Galileu, chegando até sua afirmação com os pressupostos da geometria analítica e a ideia da natureza de René Descartes (res extensa ["coisa extensa"]). Foucault (1966/2000, p. 181) lembra que este momento forjou a construção de uma história natural, isto é, sendo esta "nada mais do que a nomeação do visível”. Não obstante, o conhecimento histórico conduziu suas preocupações ao visível, por seu turno, o conhecimento filosófico como o estudo do invisível e, portanto, a história sendo ela mesma natural na apreensão do mundo e da vida. Logo, as próprias ciências do espírito se constituíram positivas, seja pelo seu horizonte historicista, seja pela apropriação das bases do pensamento natural.

3) Por último, a crítica do conhecimento percorre o sentido contrário a todo pensamento positivo das ciências, isto é, o "fato" como primazia da evidência imediata do fenômeno. No campo de suas verdades, em jogo de um lado o naturalismo das ciências exatas e a criação histórica das ciências do espírito, Husserl (1911/1965) aponta que esta condição possibilitou um tipo de falsificação sobre o que elas poderiam e não poderiam fazer conforme seus modos (objetivos) de investigação (suas lógicas), assim, sem qualquer validade segura para o conhecimento. É neste cenário, que o mundo-da-vida como aparece como solo originário e pré-científico, pondo fora de vigência (entre parêntese) o mundo predicativo (objetivo) e sua tematização, isto é, entrando em jogo a redução fenomenológica como um retorno às experiências e ao mundo original (Holzer, 2010a). Portanto, conforme Goto (2013, p. 41), "O mundo-da-vida é o lugar em que se origina a experiência pré-científica, ou seja, a experiência não-teórica, mais originária, evidente e universal que implica a experiência mesma da subjetividade”. No entanto, por que se faz 
necessário por "entre parêntese" do mundo tal como se apresenta a nós e à ciência de fatos em sua objetividade?

O contraste entre subjetivo do mundo da vida e o "objetivo" do mundo "verdadeiro" reside, então, no fato de que este é uma substrução lógico-teórica, a substrução de algo principalmente não perceptível, principalmente não experienciável no seu ser-si-mesmo próprio, ao passo que o subjetivo do mundo da vida se destaca, em tudo e em qualquer coisa, precisamente pela sua efetividade. (Husserl, 1936/2012, p. 104)

Investigar o conhecimento que precede à cientificidade toma como condição esta suspensão de juízo que jaz na atitude natural (crenças, valores, etc.). O retorno ao mundo-da-vida implica não somente por entre parêntese a tese do mundo, mas sobretudo, a tarefa de realização de uma subjetividade transcendental. Esta é uma condição necessária e ao desconsiderá-la conduz a prática científica a uma negligencia do mundo-da-vida. Portanto, não basta apenas suspender as predicações existentes no mundo, mas sobretudo, a próprio consciência.

O conjunto das três críticas apontadas certamente devem ser melhor elucidadas, mas até aqui, nos interessou como elementos de problematização preliminar. Na próxima seção, iremos apresentar as contribuições e implicações do conceito mundo-da-vida na tradição da geografia humanista. Devemos considerar que o pensamento de Husserl pouco teve repercussões no pensamento geográfico de forma direta. Embora as abordagens fenomenológicas (husserlianas) na tradição da geografia humanista em meados dos anos de 1970 tenham trazido importantes contribuições, ainda carecemos de uma compreensão mais aprofundada de seu pensamento. Ainda que a presença deste filósofo tenha sido fraca, concordamos com Johnson (1983) que ao contrapor à dominância da ciência, Husserl apresentou a fenomenologia como uma alternativa e base para o conhecimento e, em certa medida, esta chamada ecoou em alguns geógrafos na década de 1970.

\section{Mundo-da-vida e experiência geográfica na tradi- ção da geografia humanista}

Geógrafos humanistas trouxeram temas próprios quando assumiu a fenomenologia como base teórico-conceitual: especialmente, espaço vivido, vida cotidiana e lugar. Em boa parte da tradição humanista foi esta a linguagem no final da década de 1970, especialmente, com Yi-Fu Tuan, Anne Buttimer, Edward Relph, entre outros. De um pensamento contrário da grande narrativa histórica da qual as ciências do espírito forjaram para si sua base de investigação, considerando Husserl (1936/2012) como um encadeamento interminável, geógrafos humanistas trouxeram a experiência (geográfica) como uma dimensão do conhecimento. Nesse sentido, o tema mundo-da-vida passou a ser o "solo" significativo da experiência humana. Vejamos esta relação fundamental.

Na crítica fenomenológica do conhecimento, o mundo não é "visto" como uma coisa apartada da vida intuitiva e objetiva. Ele se constitui, obrigatoriamente, como horizonte intencional da qual a nossa vida é dirigida. Desse modo, não haveria princípios reducionistas de sua ocorrência, quiçá dicotomias que apontasse para uma escolha idealista ou realista; trata-se de compreender, portanto, consciência-mundo e corpo-mundo: o mundo só é para consciência como a consciência só é para o mundo. Dentro deste conhecimento mexeu-se no estilo de entendimento entre sujeito e objeto. Merleau-Ponty retrata bem esta compreensão sobre o horizonte do mundo da qual o próprio homem é constituido: "Tudo aquilo que sei do mundo, mesmo por ciência, eu o sei a partir de uma visão minha ou de uma experiência do mundo sem a qual os símbolos da ciência não poderiam dizer nada” (Merleau-Ponty, 1945/1999, p. 3). Portanto, avesso à descrição objetiva pelas ciências exatas e naturais (mecânica), o mundo no pensamento fenomenológico e, sobretudo, husserliano se apresenta de tal forma, como algo que nos direciona enquanto existente.

O mundo pré-dado é o horizonte que abrange, em fluxo constante, todas as nossas metas, todos os nossos fins, passageiros e duradouros, precisamente tal como de antemão os abarca implicitamente uma consciência intencional de horizonte. [...] Mundo é o campo universal para onde estão dirigidos todos os nossos atos de experiência, de conhecimento ou de ação. (Husserl, 1936/2012, p. 117)

Geógrafos de base fenomenológica buscaram manter esta posição. Relph (1970, 1976/1979), em seus textos procurou estabelecer uma relação consistente entre fenomenologia e ciência geográfica. Para Marandola (2013), foi quem mais se dedicou às bases da fenomenologia na geografia. Antes de aprofundar nesta relação, Relph apresenta no texto alguns apontamentos já aqui assinalados: para o autor, embora haja desacordos dentro da filosofia fenomenológica, ao menos, em três aspectos há concordâncias: 1) a importância da experiência dos homens no mundo-da-vida. 2) uma oposição à ditadura e absolutismo da ciência sobre outras formas de pensamento; 3) tentativas de formular alternativas metodológicas.

Tomando como válido o pensamento fenomenológico do mundo, Relph traz o valor da intencionalidade na geografia como uma importância para elevar às atitudes humanas e suas ações, reintegrando a relação do homem com o mundo na ciência geográfica, isto é, enquanto horizonte da efetividade da vida humana. Portanto, o autor ergue que cada indivíduo tem atitudes e ações diferenciadas, ou melhor, diferentes experiências (Relph, 1970). Desse modo, os geógrafos profissionais não seriam mais 
importantes do que as experiências individuais (as "geografias pessoais”). Assim, para o autor, a relação do homem com o mundo passa a ser vista não como uma mera relação cognitiva, mas como algo que permeia todo o ser do homem. Em ultima instância, para a geografia humanista-fenomenológica trata-se de ressignificar a visão e relação do homem com a natureza (Terra): dada mecânica, agora então, unificada.

Noutro artigo posterior, "As bases fenomenológicas da Geografia”, Relph (1976/1979, p. 2) busca pensar "ideias fenomenológicas do mundo-vivido”. Ressaltamos brevemente, que os tradutores da geografia humanista anglo-saxônica, normalmente, traduzem Lebenswelt como espaço-vivido. Tem se visto, portanto, uma grande variedade nas traduções: lifeworld, life-world, mundo vivido, mundo-vivido, mundo da vida. Aqui fazemos uso como mundo-da-vida (com hífen). No primeiro texto referenciado o autor apresenta um conceito da qual deu grande mérito ao trabalho de Husserl: a intencionalidade (Bernet, Kern e Marbach, 1999). O principal lema que fundamentou esta concepção é bem conhecido: "toda consciência é consciência de alguma coisa”. Sem trocadilhos Relph remete a consciência (tema caro para o pensamento husserliano) e faz novamente ponderações:

Mas, consciência e experiência (os dois termos são virtualmente intercambiáveis em muitos escritos fenomenológicos e incluem encontros, envolvimentos e consciência de todos os tipos) não têm inflamado os interesses dos geógrafos e há poucas investigações da consciência geográfica. (Relph, 1976/1979, p. 2)

Para alguns filósofos e cientistas Husserl não foi perdoado ao promover o debate em torno da consciência e, certamente, na ciência não se teve muito interesse. Ressaltamos que não trata de compreendê-la em suas faculdades psicológicas (conteúdos), conforme a psicologia fenomenológica. Interessa-nos a consciência enquanto aquela que nos dirige em direção a algo, que apreende o nosso próprio modo de ser-no-mundo e as coisas que nos cercam e afetam. Portanto, consciência não seria um mero retorno a si mesmo, mas algo que se direciona para e no mundo e funda a possibilidade do ser. Nada obstante, o mundo-da-vida se constitui o próprio ser-e-estar-no-mundo (Marandola Jr., 2014).

No entanto, esta visão não soa de bom grado à ciência objetiva. Nesse sentido, Relph, (1976/1979) lembra que o mundo-da-vida passou a ser visto como subjetivo (no sentido pejorativo), portando, sendo considerado como abstrações (dos indivíduos e grupos). Não obstante, Relph busca esclarecer os caminhos metodológicos da fenomenologia na geografia, isto é: trata-se de descrever e não explicar as experiências imediatas. Além do mais, se faz necessário suspender as crenças e explanações existentes e, sobretudo, nossos próprios preconceitos. Este argumento entra em consonância com a "tese do mundo" que trata Husserl: por entre parêntese as predicações mundanas, assim como, fazer a suspensão de juízos.

Em busca de clarificar e ampliar a interpretação do mundo-da-vida para a ciência geográfica, Relph apresenta suas variações essências, pouco elucidado na ciência. Para o autor há dois (eles se relacionam): 1) mundo prédeterminado ou natural. "Este mundo é o que vemos e sentimos", isto é, estamos nele implicados, diante de situações que nos é dada. 2) O mundo social ou cultural, ou seja, o "mundo-vivido da intersubjetividade, linguagem comum, contato com outras pessoas, instrumentos, edifícios e obras de arte” (Relph, 1976/1979, p. 5-6). Diante dessas condições, o autor considera que há estruturas e experiências, portanto, há um mundo-da-vida geográfico. Amatuzzi, (2009, p. 94) considera que "[...] se o homem pudesse considerar sua experiência, com tudo que nela está implicado, abstendo-se do julgamento espontâneo da realidade que ela encerra, ele poderia chegar a conclusões seguras acerca do conhecimento e seu alcance”.

De fato, o mundo-da-vida torna-se o palco da própria condição da experiência do qual as ciências modernas negligenciaram, isto é, a recusa de um implica, necessariamente, a exclusão do outro. Portanto, o potencial da experiência geográfica ancorada nas investigações fenomenológicas não se sustenta se a colocarmos meramente na vivência objetiva do mundo, mas sim, se a encontrarmos nas estruturas do mundo-da-vida. Nesse sentido, o conhecimento não viria antes da experiência e nem depois - como um subproduto resultante.

Por seu turno, Buttimer (1976) buscou conduzir a relação da fenomenologia com as definições do mundo-davida. Já na primeira parte de seu texto, argumenta que houve dificuldades em relacionar a noção de mundo-davida à linguagem geográfica, no entanto, acredita que esta noção fornece um bom início de diálogo entre fenomenologia e geografia. "Mundo vivido sugere essencialmente as dimensões pré-reflexivas e tomadas como certas, das experiências, os significados não questionados e determinantes do comportamento" (Buttimer, 1976/1985, p. 172). Com efeito, a autora traz a fenomenologia como a potencialidade de clarificar a experiência humana no espaço e destaca o dualismo que promoveu a escola positivista entre mundo interior e exterior da experiência. Tentando superar um ponto de vista dicotômico subjetivo ou objetivo da ciência, a autora considera "o modo intersubjetivo" (modo fenomenológico) como caminho para elucidar o estudo do mundo-da-vida. Isso se daria pelas considerações do estudo do comportamento das pessoas, seus significados, os valores constituídos culturalmente, isto é, o que ela chamou de vida diária (Lebenswelt). Desse modo, o mundo-da-vida poderia ser considerado como substrato da experiência. Antecipando um juízo, mas sem aprofundamento neste momento, não compreendemos o mundo-da-via como substrato ou algo complementar das experiências; aqui entendemos como esfera normativa da vida social. 
Habermas (1981/2012, p. 219) no capítulo VI do subtítulo "O conceito 'mundo da vida' e o idealismo da sociologia hermenêutica", traz um pensamento crítico que aqui estamos de acordo: "Os conceitos de mundo da vida, comuns na sociologia hermenêutica, tem a ver, na maioria das vezes, com conceitos cotidianos que apenas narram fatos e relações sociais". Relph (1976/1979, p. 4) tem um pensamento similar: "[...] os significados originais do mundo-vivido estão constantemente sendo obscurecidos por conceitos científicos e pela adoção de convenções sociais". Ainda que Habermas tenha feito ponderações a este respeito não entendeu, com intenção ou não, do mundoda-vida como normativo, mas sim, como um conceito complementar (fenomênico) do agir comunicativo - este último, por excelência, normativo. Assai expõe esta problematização em torno da tese de Habermas.

[...] em primeiro lugar, se uma Teoria Crítica postula a tese de uma teoria da sociedade normativa e, na concepção de Habermas, a teoria da sociedade é formada basicamente pelo mundo da vida e pelo sistema; então, em segundo, a normatividade aqui deveria ser entendida como um dever-ser já presente na própria estrutura formal e conteudal de mundo da vida contida na teoria da sociedade. (Assai, 2014, p. 216)

Relph (1976/1979) e igualmente Buttimer, apontam que o mundo-da-vida é da intersubjetividade (linguagem, cultura, etc.). Diante do apresentado, algumas interrogações emergem e que ficam para pensamentos futuros: Seria este, ainda hoje, o caminho ideal de fundamentação do mundo-da-vida para uma "geografia fenomenológica"? Quais as implicações de compreender o mundo-da-vida como fenômeno ou normativo na ciência geográfica? Quais os limites ou os marcos conceituais entre mundoda-vida e espaço-vivido? Husserl traz ponderações das quais nos servem como alerta.

As ciências estão construídas sobre a obviedade do mundo da vida, porquanto a partir dela fazem uso daquilo que, em cada caso, é necessário para os seus fins. Contudo, utilizar o mundo da vida desta maneira não quer dizer conhecê-la cientificamente a ele mesmo no seu modo de ser próprio. (Husserl, 1936/2012, p. 102)

Pickles (1985) relata que o mundo-da-vida ganhou um sentido muito próprio na geografia a partir da condição da experiência, isto é, houve particularidades por alguns geógrafos humanistas ao trazerem este tema: mundo cotidiano da experiência imediata, modos culturalmente variáveis de existência. Um ponto comum, que tanto Buttimer e Relph trás nas suas abordagens em relação ao tema mundo-da-vida é a experiência humana no espaço, avesso ao espaço matematizado e geométrico. Conforme Relph (1976/1979), do ponto de vista fenomenológico, os espaços não são vazios, assim, haveria uma consciência intencional geográfica - o indivíduo experienciando e a coisa experienciada. Nesse sentido, o espaço agora então vivido (ou existencial) torna-se quase um subproduto ou uma derivação do conceito de mundo-da-vida. Portanto, ainda que o mundo-da-vida tenha ganhado um espaço no pensamento da tradição da geografia humanista, não se tornou fundamento. Se preservou, com razão, a categoria espaço (vivido) como normativo das estruturas e relações sociais, por outro lado, histórico e ontológico.

Ainda que Pickles (1985) lembre que a experiência geográfica é a priori da ciência geográfica - ontologicamente e historicamente -, e Dardel (1952/2011) erga uma geografia pré-científica, estas considerações deixam de tratar o mundo-da-vida como o conceito fundante e, por excelência, "o domínio das evidencias originárias" (Husserl, 1936/2012, p. 104). O espaço geográfico ou vivido nos abriria esta possibilidade originária das essências? Goto (2013) considera que para Husserl as experiências originárias tem sua ocorrência no mundo-da-vida e, portanto, acreditamos que para captá-la geograficamente em seu rigor, há a necessidade da constituição de uma geografia fenomenológica ou uma geografia eidética.

Portanto, o rigor de uma geografia fenomenológica requer a possibilidade de buscar o seu próprio fundamento. Caso deseje, romper com a arbitrariedade científica deve iniciar no solo do mundo-da-vida em seu horizonte ontológico e transcendental e, por outro lado, sem qualquer compreensão similar com a ontologia social do espaço (espaço construído historicamente pelas sociedades). Ainda que muitos geógrafos humanistas tenham abandonado a abordagem fenomenológica, Marandola Jr. (2013) lembra, que a busca pela renovação cumpriu seu papel.

\section{Considerações para uma geografia fenomenológica}

Marandola Jr. (2013) em discussão das transformações recentes da abordagem fenomenológica na geografia humanista, sinaliza que a constituição de uma geografia fenomenológica não chegou ser claramente esboçada na tradição. Isso não quer dizer que houve falhas ou erros, certamente, talvez este não teria sido o objetivo essencial daqueles geógrafos humanistas do século passado. Cabe ponderar, que o acesso às obras de Husserl contribui de forma decisiva; além de serem filosóficas e densas, seus manuscritos vão para interpretes ou ficam em obras mais conhecidas.

De todo modo, parece válido quando Entrikin (1976) alerta que a tradição fenomenológica na geografia não pretendeu alguma alternativa, pois se preocupou mais no seu horizonte crítico. Certamente, isso teve consequências: 1) o pensamento crítico de uma escola, de um filósofo, de um certo grupo é sempre vivente de seu tempo, de sua condição política, social, etc. Desse modo, fica pertencente a uma tradição que pode ser renovado ou não. 2) No entanto, quando o pensamento crítico tem pretensões 
de fundamentar alternativas teóricas e metodológicas (teleológicas) sua finalidade torna-se tematizada. Portanto, a tradição da "geografia fenomenológica" perdeu forma antes mesmo dos anos de 1990 e hoje é praticamente ausente nos países que iniciaram o pensamento. No entanto, deixou valiosas contribuições que hoje se segue.

Para Marandola Jr. (2013) no Brasil o projeto fenomenológico se inicia nos anos de 1990 e, no cenário atual, vislumbramos trabalhos que apontam para a constituição de uma geografia fenomenológica, especialmente, a partir das obras de Heidegger no que tange a compreensão do ser-no-mundo (Holzer, 2010a, Marandola, 2012). $\mathrm{O}$ caminho que aqui se pretende, busca uma via direta pelas ideias de Edmund Husserl, como igualmente, pretendeu Goto (2013) em seu recente artigo: "Fenomenologia, mundo-da-vida e crise das ciências: a necessidade de uma geografia fenomenológica".

Em nosso objetivo, acreditamos que o caminho fiel para tal pretensão se dará pela elucidação de uma "geografia fenomenológica do mundo-da-vida”. Não há dúvida que a geografia no decorrer de sua institucionalização foi se afastando das suas bases originárias - o olhar para o mundo e para Terra. Como aponta Goto (2013, p. 43) a cientificidade da geografia "[...] ignora a vivência do saber imediato que o humano tem com a Terra (natureza), com suas configurações”. Com isso, torna exigente uma geografia eidética que resgate o sentido primeiro de seu fundamento, isto é, seu campo de fundamentação e sentido. De certo, o resgate de uma geografia que precede sua própria cientificidade está no solo das evidências originárias do mundo-da-vida e, portanto, a necessidade de uma geografia fenomenológica requer elucidar um campo fenomenológico, uma geografia eidética (Goto, 2013). Dardel quem influenciou decisivamente os geógrafos humanistas na década de 1970 (Holzer, 2010b, 2001) vislumbrou uma necessidade similar: "A geografia não é, de início, um conhecimento" (Dardel, 1952/2011, p. 33). Desse modo, a ciência geográfica não pressupõe um mundo geográfico, mas ao contrário, que o mundo seja apreendido geograficamente.

O que está em rigor neste pensamento é a própria ideia da fenomenologia: deixar ver por si mesmo o que se manifesta (fenômeno e logos) ou a manifestação por si mesmo. Assim, apreender é o deixar manifestar por si mesmo (em nós mesmo), uma geografia originária e evidente (intuitiva). Isso implica que o objeto geográfico não pode ser uma determinação científica, mas sim, o domínio das percepções possíveis (externas e internas). Diante de uma geografia existencial Dardel (1952/2011, p. 43) buscou reerguer a Terra como fundamento essencial, isto é, "[...] para o homem, como destino, a circunstância (circumstare), aquilo que se ergue à sua volta e mantém sua presença como engajamento no Ser".

Nesse sentido, Dardel toma a Terra como um encontro imediato do homem, embora sobre as ideias fenomenologia de Heidegger, no entanto, abre caminhos pertinen- tes e elucidativos para uma incursão do tema mundo-davida como ferramenta que descortine uma compreensão originária entre o homem, mundo e a Terra. Se a relação do homem com a Terra é um acontecimento imediato, o mundo-da-vida enquanto possibilidade de ver no seu modo de ser próprio, seu estudo torna-se horizonte temático, agora então, para a geografia fenomenológica. Além do mais, enquanto domínio das evidencias originárias requer uma geografia eidética que investigue o campo das intuições e das essências - para usar um termo de Dardel cunhado termo de Relph: investigar a "consciência geográfica”. Com efeito, o espaço (geográfico ou vivido) tornou-se em nosso entender abstração, ainda que reconhecemos os esforços de compreendê-lo histórico-social. Nesse sentido, que o conceito do mundo-da-vida passar ser tematizado na ciência geográfica, não como um tema que deriva para o estudo do lugar ou do espaço vivido, mas sim, a própria tarefa de uma geografia fenomenológica.

\section{Referências}

Amatuzzi, M. M. (2009). Psicologia fenomenológica: uma aproximação teórica humanista. Estudos de Psicologia, 26(1), 93-100.

Assai, J. H. S. (2014). A ontologia social "fraca" em Habermas: 0 déficit normativo do mundo da vida (Lebenswelt). Intuitio, 7(1), 215-225.

Bernet, R., Kern, I. \& Marbach, E. (1999). An introduction to husserlian phenomenology. Northwestern University Studies in phenomenology.

Buttimer, A. (1976). Grasping the dynamism of lifeworld, Annals of American Geographers, 66(2), 277-292.

Buttimer, A. (1985). Aprendendo o dinamismo do mundo vivido. Em Christofoletti, A. Perspectivas da geografia (p. 165-193). São Paulo: Difel. (Originalmente publicado em 1976)

Casey, E. S. (2001). Between Geography and Philosophy: what does it mean to be in the place-world? Annals of the Association of American Geographers, 91(4), 683-693.

Dardel, E. (2011). O Homem e a Terra: natureza da realidade geográfica. Tradução de Werther Holzer. São Paulo: Perspectiva. (Originalmente publicado em 1952)

Dartigues, A. (1992). O que é fenomenologia? Tradução de Maria José J.G. de Almeida. São Paulo: Moraes. (Originalmente publicado em 1972)

Dilthey, W. (2010). A construção do mundo histórico. Tradução de Marco Casanova. São Paulo: Edusp. (Originalmente publicado em 1910)

Entrikin, J. N. (1976). Contemporary Humanism in Geography, Annals of the Association of American Geographers, 66(4), 615-632. 
Estébanez, J. A. (1982). La geografia humanística. Anales de la Universidad Camplutense, 2, 11-31.

Ferraz, M. S. A. (2004). Lições do mundo-da-vida: o último Husserl e a crítica ao objetivismo. Scientiæ Studia, 2(3), 355-372.

Ferreira, R. B. (2015, outubro). As estruturas do mundo-da-vida e seu significado para a Geografia. Trabalho apresentado no XI Encontro Nacional da ANPEGE, Presidente Prudente/SP.

Foucault, M. (2000). As palavras e as coisas: uma arqueologia das ciências humanas. São Paulo: Martins Fontes. (Originalmente publicado em 1966)

Goto, T. A. (2013). Fenomenologia, mundo-da-vida e crise das ciências: a necessidade de uma geografia fenomenológica. Geograficidade, 3(2), 33-48.

Habermas, J. (2012). Teoria do agir comunicativo (V. 2). Tradução Fábio Beno Siebeneichler. São Paulo: Editora WMF Martins Fontes. (Originalmente publicado em 1981)

Holzer, W. (2001). A geografia fenomenológica de Eric Dardel. Em Correa, R. L. \& Rosendahl, Z. Matrizes da geografia cultural (p. 103-122). Rio de Janeiro: EDUERJ.

Holzer, W. (2010a). A construção de uma outra ontologia geográfica: a contribuição de Heidegger. Geografia, 35(2), 241-251.

Holzer, W. (2010b, julho). A influência de Eric Dardel na construção da geografia humanista norte americana. Trabalho apresentado no XVI Encontro Nacional de Geógrafos. Porto Alegre.

Husserl, E. (1965). A filosofia como ciência de rigor. Tradução de Albin Beau. Coimbra: Atlântida. (Originalmente publicado em 1911)

Husserl, E. (2001). The Shorter Logical Investigations. Trans. J. N. Findlay. Ed. Dermot Moran. London: Routledge. (Originalmente publicado em 1900-1901)

Husserl. E. (2012). A crise das ciências europeias e a fenomenologia transcendental: uma introdução à filosofia fenomenológica. Tradução de Diogo Falcão Ferrer. Rio de Janeiro: Forense Universitária. (Originalmente publicado em 1936).

Johnson, L. (1983). Bracketing lifeworlds: Husserlian phenomenology as geographical Method. Australian Geographical Studies, 21(1), 102-108.

Lowenthal, D. (1961). Geography, experience, and imagination: towards a geographical epistemology, Annals of the Association of American Geographers, 51(3), 241-260.

Marandola, Jr., E. (2005). Arqueologia fenomenológica: em busca da experiência. Terra Livre Goiânia, 2(25), 67-79.

Marandola, Jr., E. (2012). Heidegger e o pensamento fenomenológico em geografia: sobre os modos geográficos de existência. Geografia, 37(1), 81-94.

Marandola, Jr., E. (2013). Fenomenologia e pós-fenomenologia: alternâncias e projeções do fazer geográfico humanista na geografia contemporânea. Geograficidade, 3(2), 49-64.

Marandola, Jr., E. (2014, abril). Um sentido fenomenológico de paisagem: o sentir em mistura do ser-lançado-no-mundo.
Trabalho apresentado no Seminário Internacional "Questões Contemporâneas sobre Paisagem”. Faculdade de Arquitetura e Urbanismo, USP.

Merleau-Ponty, M. (1999). Fenomenologia da percepção. Tradução Carlos Alberto Ribeiro de Moura. 2. ed. São Paulo: Martins Fontes. (Tópicos) (Originalmente publicado em 1945)

Moran, D. (2002). Introduction to phenomenology. London and New York: Routledge.

Moreira, R. (2000). Assim se passaram dez anos (A renovação da geografia no Brasil no período 1978-1988). GEOgraphia, 2(3), 27-49.

Pickles, J. (1985). Phenomenology, science and geography: spatiality and the human sciences. Cambridge: Cambridge University Press.

Relph, E. C. (1970). An inquiry into the relations between phenomenology and geography, Canadian Geographer, 14(3), 193-201.

Relph, E. C. (1979). As bases fenomenológicas da Geografia, Geografia, 4(7), 1-25. (Originalmente publicado em 1976)

Sanguin, A. (1981). La géographie humaniste ou l'approche phénoménologique des lieux, des paysages et des espaces. Annales de Géographie, 90(501), 560-587.

Rafael Bastos Ferreira - Possui Licenciatura e Bacharelado em Geografia pela Universidade Federal do Amapá, com Especialização em Extensão Rural, Sistemas Agrários e Ações de Desenvolvimento pela Universidade Federal do Pará e Mestrado em Ciências Humanas e Sociais Aplicadas pela Universidade Estadual de Campinas (FCA/Unicamp). Membro dos Grupos de Pesquisa Geografia Humanista Cultural (UFF) e Fenomenologia e Geografia (FCA/Unicamp). Endereço Institucional: Faculdade de Ciências Aplicadas da Unicamp - R. Pedro Zaccaria, 1300. Caixa Postal 1068, CEP: 13484-350 - Limeira - São Paulo. E-mail: rafael.ferreira@fca.unicamp.br

Recebido em 26.04.2016 Primeira Decisão Editorial em 04.08.2016 Aceito em 23.08.2016 